OPEN ACCESS

Edited by:

Shan Zheng,

Children's Hospital, Fudan

University, China

Reviewed by:

Iori Sato,

The University of Tokyo, Japan Giovanna Riccipetitoni, San Matteo Hospital Foundation

(IRCCS), Italy

*Correspondence:

Lizhi Li

1755806886@qq.com

Yi Ji

jijiyuanyuan@163.com

Specialty section: This article was submitted to Children and Health,

a section of the journal

Frontiers in Pediatrics

Received: 04 June 2021

Accepted: 31 January 2022

Published: 24 February 2022

Citation:

Dai S, Yang K, Qiu T, Zhou J, Zhang X,

Chen S, Li L and Ji Y (2022)

Health-Related Quality of Life in

Children With Kaposiform

Hemangioendothelioma.

Front. Pediatr. 10:720611

doi: 10.3389/fped.2022.720611

\section{Health-Related Quality of Life in Children With Kaposiform Hemangioendothelioma}

\author{
Shiyi Dai ${ }^{1}$, Kaiying Yang ${ }^{1}$, Tong Qiu ${ }^{1}$, Jiangyuan Zhou ${ }^{1}$, Xuepeng Zhang ${ }^{2}$, Siyuan Chen ${ }^{2}$, \\ Lizhi Li ${ }^{3 *}$ and $\mathrm{Yi} \mathrm{Ji}^{1 *}$ \\ ${ }^{1}$ Division of Oncology, Department of Pediatric Surgery, West China Hospital of Sichuan University, Chengdu, China, \\ ${ }^{2}$ Pediatric Intensive Care Unit, Department of Critical Care Medicine, West China Hospital of Sichuan University, Chengdu, \\ China, ${ }^{3}$ Department of Pediatric Surgery, Shengli Clinical Medical College of Fujian Medical University, Fuzhou, China
}

Background and Objective: Kaposiform hemangioendothelioma (KHE) is a rare, aggressive and borderline vascular tumor mainly occurring in infants and children. The aim of this study was to determine the health-related quality of life (HRQOL) in children with $\mathrm{KHE}$.

Measures: A total of 91 children with KHE participated in this cross-sectional study. The HRQOL was assessed by the age-specific Pediatric Quality of Life Inventory Version 4.0 (PedsQL ${ }^{\text {TM }}$ 4.0) Infant Scales, Family Information Form (FIF), Family Impact Module (FIM) and Generic Core Scales (GCS). For comparison, demographically matched healthy children were recruited as a control group. The main outcome measure of HRQOL was analyzed in the two groups. We determined related factors that influenced the HRQOL in children with $\mathrm{KHE}$ and their parents by using a stepwise multiple regression analysis.

Results: The study found that the scores of each item in the family impact module (FIM) were lower than 75 , which suggesting that KHE can make the parents of patients in a state of poor quality of life. The scores of physiological and psychosocial domains in all age groups of patients with KHE were lower than those of normal children $(P<0.01)$. Activity dysfunction is the factor influencing the physiological function score of all-age patients. KMP is the factor influencing the psychosocial function score of all-age patients.

Conclusions: The findings presented here suggest that patients with KHE have a poor HRQOL. KMP and activity dysfunction are risk factors for poor HRQOL in patients with KHE. However, lesion size, lesion location and education level of the mother and father were not related to the HRQOL.

Keywords: kaposiform hemangioendothelioma, Kasabach-Merritt phenomenon, quality of life, PedsQL ${ }^{\mathrm{TM}} 4.0$, vascular tumor

\section{INTRODUCTION}

Kaposiform hemangioendothelioma (KHE) is a rare, endodermic, aggressive and borderline vascular tumor mainly occurring in infants and children (1). The incidence rate of KHE is $0.0091 \%$ \% (2). Approximately $70 \%$ of KHE cases are associated with thrombocytopenia, coagulation factor depletion and severe anemia, known as the Kasabach-Merritt phenomenon (KMP) (3). In recent years, multiple lesions and complex cases of KHE have been increasingly reported (4-8). However, 
there is currently no appropriate assessment of quality of life (QOL) in patients with KHE. It is still unknown whether KHE affects the QOL in children with KHE and their parents.

Health-related QOL (HRQOL) is a psychosocial response to a patient's disease and treatment. The HRQOL is affected by the disease itself, treatment and long-term complications. Quantitative assessments of QOL have resulted in substantial changes in health measurements. We know that the QOL in normal children is related to family economic status, the intimate relationship between family members, level of socioeconomic culture development and the behavior concept of children's education. We suspect that the frequency and severity of disease onset, negative emotions such as anxiety and depression, an insufficient understanding of the disease by parents or other factors may have an effect and are worth exploring $(9,10)$. For evaluating HRQOL in patients with KHE, we know that the progression of the KHE disease is often accompanied by life-threatening KMP and musculoskeletal complications. KHE can cause damage to children's joint function, resulting in long treatment and recovery time. Some cases of KHE are disabled and deformed. The influence of the lesion itself, the sequelae of surgical treatment, and the side effects of long-term use of hormones, vincristine, sirolimus and other drugs may affect the normal life of children. Therefore, we need to pay special attention to the QOL of in children with KHE, and take corresponding measures to improve their QOL and avoid psychological and social behavior problems in their growth stage.

In the present study, we used the objective Pediatric QOL Inventory Version 4.0 (PedsQL ${ }^{\mathrm{TM}} 4.0$ ) scale to evaluate patients with KHE, explore the impact of the disease on patients and understand the main factors affecting patients' HRQOL. In this way, we assessed the HRQOL of KHE children and their parents as well as the main influencing factors and developed targeted intervention measures to improve their HRQOL.

\section{METHODS}

\section{Participants}

The research was conducted in the Pediatric Surgery Department, West China Hospital of Sichuan University and the Department of Children Preventive Health Care, West China Second Hospital. Both hospitals are tertiary medical centers that serve children referred by pediatricians and surgeons. This study was approved by the ethics committees of the West China Hospital of Sichuan University and West China Second University Hospital of Sichuan University. All procedures followed approved research protocols. We recruited 0-14-year-old children diagnosed with KHE at the Department of Pediatric Surgery, West China Hospital of Sichuan University, and coetaneous healthy children at the Department of Children Preventive Health Care, All the recruited patients were newly diagnosed with KHE by

\footnotetext{
Abbreviations: KHE, Kaposiform hemangioendothelioma; HRQOL, healthrelated quality of life; KMP, Kasabach-Merritt phenomenon; QOL, quality of life; PedsQL ${ }^{\mathrm{TM}}$ 4.0, Pediatric Quality of Life Inventory Version 4.0; FIF, Family Information Form; FIM, Family Impact Module; GCS, Generic Core Scales; SD, standard deviation.
}

a multidisciplinary vascular anomaly group (a collaboration team including $\mathrm{IH}$ experts in pediatric surgery, plastic surgery, pediatric dermatology and radiology) at our hospital. West China Second Hospital, from January 2018 to July 2020. The parents of the children enrolled in the study signed informed consent forms. All questionnaires were completed and received at the time of enrollment.

\section{Instruments}

All children and parents were administered a questionnaire to assess the HRQOL. The PedsQL ${ }^{\mathrm{TM}}$ 4.0 Chinese versions, which contain the Family Information Form (FIF), Family Impact Module (FIM), Generic Core Scales (GCS) and Infant Scales, were assessed. The PedsQL ${ }^{\mathrm{TM}} 4.0$ is a reliable and validated multidimensional modular approach to measuring HRQOL in children and adolescents (11-14). The PedsQL ${ }^{\mathrm{TM}}$ 4.0 GCS includes physiological and psychosocial domains which consists of 4 functional domains, including physical, emotional, social, and school functioning, and 4 different ages groups: 2-4 years (21 items), 5-7 years (23 items), 8-12 years (23 items), and 1318 years (21 items). The PedsQL ${ }^{\mathrm{TM}} 4.0$ Infant Scales were used for children aged 1-12 and 13-24 months. The 1-12 month scale contains 38 items, and the 13-24 month scale contains 45 items. Both cover 5 functional domains: physical, physical symptom, emotional, social and cognitive functioning. Each item is a question on the frequency of something happening in the last month. KHE children and their parents were required to complete the PedsQL ${ }^{\mathrm{TM}} 4.0$ GCS or PedsQL ${ }^{\mathrm{TM}} 4.0$ Infant Scales, PedsQL ${ }^{\mathrm{TM}}$ 4.0 FIF and PedsQL ${ }^{\mathrm{TM}}$ 4.0 FIM. Healthy children and their parents needed to complete only the PedsQL ${ }^{\mathrm{TM}} 4.0$ GCS or PedsQL ${ }^{\mathrm{TM}}$ 4.0 Infant Scales and PedsQL ${ }^{\mathrm{TM}} 4.0$ FIF. The questionnaires for the age groups 1-12 months, 13-24 months, and 2-4 years were answered by parents, whereas the questionnaires for the age groups 5-7, 8-12, and 13-18 years were answered by both the children themselves and their parents. All questionnaires used a Likert-type scale, where 0 was never, 1 was almost never, 2 was sometimes, 3 was often and 4 was almost always. Scores of $0-4$ for each item were converted to a $0-100$ scale $(0=100,1=75,2=50,3=25,4=0)$. Scores for each item ranged from 0 to 100 , and high scores indicated a good HRQOL. Furthermore, questionnaires with incomplete basic information and more than half of items missing were considered invalid.

\section{Procedures}

Before completing the questionnaire, we obtained informed consent from the parents and provided a good explanation of the purpose and significance of the research. Under the supervision of trained physicians, when necessary, the staff explained the study to the parents individually. The children themselves or their parents filled in the general information and questionnaire items. Children who were older than 5 years of age completed the PedsQL ${ }^{\mathrm{TM}} 4.0$ scale module independently. In addition, the clinical data of patients with KHE were reviewed after verification by 2 investigators. 


\section{Statistical Analysis}

The general characteristics of the patients with KHE are presented using descriptive statistics. For quantitative data with a normal distribution, the mean \pm standard deviation (SD) is presented. Independent sample $t$-tests were used for comparisons of differences between groups. For quantitative data with a nonnormal distribution, medians with interquartile intervals are presented. For categorical data, comparisons between groups were performed using chi-square $\left(\chi^{2}\right)$ tests and multiple regression analysis. $P<0.05$ was considered to be statistically significant. All statistical analyses were performed with SPSS 24.0 statistical software (SPSS Inc., Chicago, USA).

\section{RESULTS}

In total, 182 questionnaires were distributed, and 177 questionnaires were effectively recovered, with a recovery rate of $97.25 \%$. A total of 177 children participated in the study, including 91 patients with KHE (54 male, 37 female) and 86 healthy children (47 male, 39 female). The mean age of the patients was $35.82 \pm 41.27$ months, media age was 18 months, range from 1 months to 165 months (IQR 5-59). The mean age of the healthy children was $36.10 \pm 41.63$ months, media age was 22.5 months, range from 1 months to 157 months (IQR 11-40.75). According to the applicable scales, we divided the participants into two age groups (age $\leq 24$ months and age $>24$ months). Table 1 shows the baseline characteristics of the children with KHE and those in the normal group. Age, gender,

TABLE 1 | Baseline characteristics of the children in the KHE and normal groups.

\begin{tabular}{|c|c|c|c|}
\hline \multirow[t]{2}{*}{ Variables } & KHE & Normal & $P$-values \\
\hline & $n=91$ & $n=86$ & \\
\hline $\mathrm{Age}^{\dagger}$ & $35.82 \pm 41.27$ & $36.10 \pm 41.63$ & 0.344 \\
\hline Age $\leq 24$ months & 53 (58.24\%) & 43 (50.00\%) & \\
\hline Age $>24$ mouths & $38(41.76 \%)$ & 43 (50.00\%) & \\
\hline Gender $^{\ddagger}$ & & & 0.527 \\
\hline Male & 54 (59.34\%) & 47 (54.65\%) & \\
\hline Female & 37 (40.66\%) & $39(45.35 \%)$ & \\
\hline $\begin{array}{l}\text { Relationship between the } \\
\text { respondents }{ }^{\ddagger}\end{array}$ & & & 0.568 \\
\hline Father & 25 (27.47\%) & $18(20.93 \%)$ & \\
\hline Mother & 52 (57.14\%) & 52 (60.47\%) & \\
\hline Father and mother & 14 (15.39\%) & 16 (18.60\%) & \\
\hline Mother's education level ${ }^{\ddagger}$ & & & 0.928 \\
\hline Elementary education & 19 (20.88\%) & $16(18.60 \%)$ & \\
\hline Secondary education & 18 (19.78\%) & 18 (20.93\%) & \\
\hline Higher education & $54(59.34 \%)$ & $52(60.47 \%)$ & \\
\hline Father's education level ${ }^{\ddagger}$ & & & 0.664 \\
\hline Elementary education & $21(23.08 \%)$ & 18 (20.93\%) & \\
\hline Secondary education & $19(20.88 \%)$ & $14(16.28 \%)$ & \\
\hline Higher education & $51(56.04 \%)$ & 54 (62.79\%) & \\
\hline
\end{tabular}

KHE, Kaposiform hemangioendotheliomas; KMP, Kasabach-Merritt phenomenon.

${ }^{\dagger}$ Data are shown as the mean and standard deviation.

¥Values are presented as the number (percentage). the relationship between the respondents, and mother's or father's education level were not significantly different between the KHE group and the control group.

The demographic details and clinical data of the KHE group are listed in Table 2. Among the 91 study subjects, the average tumor diameter was $7.91 \pm 4.32 \mathrm{~cm} .48(52.75 \%)$ patients had KMP, and $43(47.25 \%)$ patients did not. The tumors were located on the head, face or neck in $23(25.27 \%)$ cases, trunk in 32 $(35.16 \%)$ cases, and extremities in $36(39.56 \%)$ cases. Activity dysfunction in children with KHE was reported in 32 (35.16\%) cases, and $59(64.84 \%)$ cases were not associated with activity dysfunction. Some of the patients developed complications, including decreased range of motion, severe pain, coagulation disorders, active organ bleeding, etc.

FIM showed that the scores of family members of patients with KHE in physiology, emotion, society, cognition, communication, worry, daily activities, family relationship and family financial burden were lower than 75 , indicating that the parents of patients were in poor quality of life and KHE can reduce the quality of life of patients' guardians. We found that the scores of physiological and psychosocial function domains of patients with KHE were lower than those of normal children (all $P<0.01$ ). The scores of HRQOL physiological and psychosocial function of the $>24$ months group were lower than the $\leq 24$ months group.

Through the analysis of the influencing factors of HRQOL in patients with $\mathrm{KHE}$, we found that the activity dysfunction was the factor influencing the score of physiological function, and KMP was the factor influencing the score of psychosocial function. In practical terms, The scores of each instrument in the patient group and healthy group are shown in Tables 3-5.

TABLE 2 | Demographic details and clinical data of the KHE group $(n=91)$.

\begin{tabular}{lc} 
Variable & No. (\% of total) \\
\hline Tumor size (average diameter in cm) & $7.91 \pm 4.32$ \\
KMP & \\
With KMP & $48(52.75 \%)$ \\
Without KMP & $43(47.25 \%)$ \\
Activity dysfunction & \\
With activity dysfunction & $32(35.16 \%)$ \\
Without activity dysfunction & $59(64.84 \%)$ \\
Location & \\
Head face and neck & $23(25.27 \%)$ \\
Trunk & $32(35.16 \%)$ \\
Extremity & $36(39.56 \%)$ \\
Complications & \\
Decreased range of motion & $32(35.16 \%)$ \\
Severe pain & $9(9.89 \%)$ \\
Coagulation disorders & $48(52.75 \%)$ \\
Active organ bleeding & $4(4.40 \%)$ \\
Acute heart failure & $3(3.30 \%)$ \\
Pleural effusion & $2(2.19 \%)$ \\
Pericardial effusion & $5(5.49 \%)$
\end{tabular}

KHE, Kaposiform hemangioendotheliomas; KMP, Kasabach-Merritt phenomenon. 
There were significant differences in physical functioning, physical symptom functioning and emotional functioning in the PedsQL ${ }^{\mathrm{TM}} 4.0$ Infant Scales $(P<0.05)$ scores between the $\leq 24$ months group and the healthy $\leq 24$ months group. However, no significant difference was revealed in social functioning and cognitive functioning $(P>0.05)$. Interestingly, when we used the PedsQL ${ }^{\mathrm{TM}} 4.0$ GCS to compare the patients age $>24$ months with the healthy children aged $>24$ months, we found that physical, emotional, social and cognitive functioning were significantly different $(P<0.05)$.

Tables 6, 7 show the differences in the scores of each instrument between the two patient subgroups (aged $\leq 24$ vs. aged $>24$ months). In the $\leq 24$ months group, there were significant differences in the HRQOL between patients with and without KMP in physical symptoms and physical and emotional functioning $(P<0.05)$. In the age $>24$ months group, the

TABLE 3 | Scores of each instrument in the patient group and healthy group.

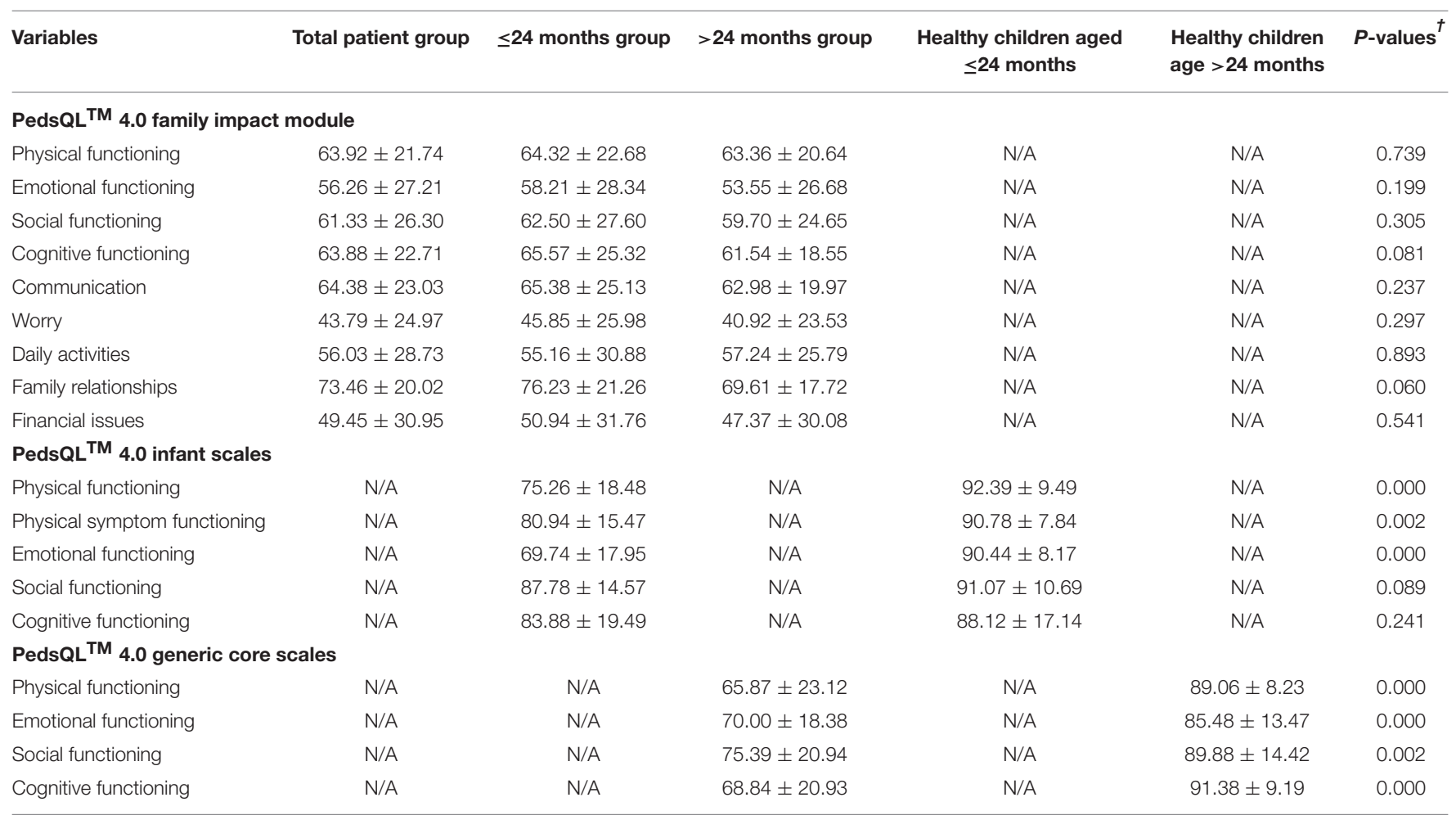

Data are shown as the mean and standard deviation; N/A not available.

${ }^{\dagger}$ For PedsQL ${ }^{T M} 4.0$ Family Impact Module, P-values represent patients aged $\leq 24$ months compared with patients aged $>24$ months; For the PedsQL ${ }^{T M} 4.0$ Infant Scales and PedsQL ${ }^{T M} 4.0$ Generic Core Scales, $P$-values represent the patients groups compared with healthy children.

TABLE 4 | Scores of physiological and psychosocial functions in children with KHE and normal children.

\begin{tabular}{|c|c|c|}
\hline & Physiological function mean $\pm \mathrm{SD} / 95 \% \mathrm{Cl}$ & Psychosocial function mean $\pm \mathrm{SD} / 95 \% \mathrm{Cl}$ \\
\hline Total healthy children group & $90.63 \pm 8.29(88.86-92.41)$ & $89.99 \pm 8.48(88.17-91.81)$ \\
\hline Total patient group & $73.67 \pm 19.08(69.70-77.65)$ & $77.73 \pm 15.76(74.45-81.01)$ \\
\hline$P$-values & $P<0.01$ & $P<0.01$ \\
\hline \multicolumn{3}{|l|}{ PedsQL ${ }^{T M} 4.0$ infant scales } \\
\hline$\leq 24$ months healthy children group & $91.88 \pm 8.20(89.35-94.40)$ & $89.74 \pm 8.91(87.01-92.48)$ \\
\hline \multicolumn{3}{|l|}{ PedsQL ${ }^{T M} 4.0$ generic core scales } \\
\hline$>24$ months healthy children group & $89.39 \pm 8.28(86.84-91.94)$ & $90.24 \pm 8.12(87.74-92.74)$ \\
\hline$>24$ months patient group & $67.50 \pm 22.71(60.04-74.97)$ & $73.92 \pm 16.64$ (68.45-79.39) \\
\hline$P$-values & $P<0.01$ & $P<0.01$ \\
\hline
\end{tabular}

Mean \pm SD, mean and standard deviation; Cl, Confidence Interval. 
TABLE 5 | Multiple regression analysis of factors influencing quality of life score of patients with KHE.

\begin{tabular}{|c|c|c|c|c|}
\hline & Coeff (B) & Std Coeff $(\beta)$ & Significance ( $P$-value) & $95 \% \mathrm{Cl}$ \\
\hline \multicolumn{5}{|l|}{ Physiological function } \\
\hline KMP & 0.006 & 0.194 & 0.065 & $0.960(0.913-1.011)$ \\
\hline Activity dysfunction & 0.005 & 0.003 & 0.048 & $1.071(1.020-1.125)$ \\
\hline Location & -0.007 & -0.293 & 0.059 & $1.014(0.963-1.068)$ \\
\hline Mother's education level & 0.006 & 0.140 & 0.183 & $0.957(0.890-1.029)$ \\
\hline Father's education level & 0.008 & 0.191 & 0.069 & $1.019(0.941-1.105)$ \\
\hline \multicolumn{5}{|l|}{ Psychosocial function } \\
\hline $\mathrm{KMP}$ & 0.007 & 0.266 & 0.011 & $1.125(1.052-1.203)$ \\
\hline Activity dysfunction & -0.013 & -0.193 & 0.061 & $0.955(0.898-1.015)$ \\
\hline Location & -0.004 & -0.130 & 0.220 & $0.974(0.913-1.040)$ \\
\hline Mother's education level & 0.006 & 0.122 & 0.248 & $1.023(0.936-1.117)$ \\
\hline Father's education level & 0.008 & 0.154 & 0.145 & $0.905(0.814-1.007)$ \\
\hline
\end{tabular}

OR, odds ratio; Cl, Confidence Interval; Coeff, coefficient; Std Coeff, standard coefficient.

TABLE 6 | Analysis and score for each dimension of the PedsQL ${ }^{\mathrm{TM}} 4.0$ Infant Scales (age $\leq 24$ months).

\begin{tabular}{|c|c|c|c|c|c|}
\hline PedsQL ${ }^{\mathrm{TM}} 4.0$ Infant Scales & $\begin{array}{l}\text { Physical functioning } \\
\text { (mean } \pm \text { SD) }\end{array}$ & $\begin{array}{c}\text { Physical symptom } \\
\text { functioning (mean } \pm S D \text { ) }\end{array}$ & $\begin{array}{l}\text { Emotional functioning } \\
\qquad \text { (mean } \pm \text { SD) }\end{array}$ & $\begin{array}{l}\text { Social functioning } \\
\quad \text { (mean } \pm \text { SD) }\end{array}$ & $\begin{array}{l}\text { Cognitive functioning } \\
\text { (mean } \pm \text { SD) }\end{array}$ \\
\hline Normal group & $92.39 \pm 9.49$ & $90.78 \pm 7.84$ & $90.44 \pm 8.17$ & $91.07 \pm 10.69$ & $88.12 \pm 17.14$ \\
\hline \multicolumn{6}{|l|}{ Patient group } \\
\hline With KMP & $67.43 \pm 18.19$ & $77.03 \pm 16.45$ & $62.44 \pm 16.34$ & $81.45 \pm 15.58$ & $77.40 \pm 21.55$ \\
\hline Without KMP & $87.17 \pm 11.34$ & $86.90 \pm 11.86$ & $80.85 \pm 14.46$ & $97.44 \pm 3.63$ & $93.75 \pm 9.93$ \\
\hline$P$-value & 0.000 & 0.048 & 0.000 & 0.000 & 0.001 \\
\hline Activity dysfunction & $81.92 \pm 16.62$ & $85.89 \pm 17.25$ & $73.82 \pm 18.19$ & $92.85 \pm 13.71$ & $88.39 \pm 20.32$ \\
\hline Without activity dysfunction & $72.86 \pm 18.73$ & $79.17 \pm 14.60$ & $68.27 \pm 17.87$ & $85.96 \pm 14.60$ & $82.26 \pm 19.20$ \\
\hline$P$-value & 0.075 & 0.483 & 0.696 & 0.202 & 0.326 \\
\hline \multicolumn{6}{|l|}{ Location } \\
\hline Extremity & $71.26 \pm 18.75$ & $79.89 \pm 14.30$ & $68.47 \pm 17.09$ & $84.55 \pm 16.10$ & $81.00 \pm 23.02$ \\
\hline Trunk & $77.45 \pm 19.53$ & $84.41 \pm 12.54$ & $73.04 \pm 19.59$ & $89.63 \pm 12.24$ & $87.81 \pm 14.07$ \\
\hline Head, face or neck & $78.87 \pm 16.79$ & $78.39 \pm 20.21$ & $67.71 \pm 17.97$ & $90.63 \pm 14.66$ & $83.63 \pm 19.63$ \\
\hline$P$-value & 0.786 & 0.925 & 0.382 & 0.587 & 0.979 \\
\hline \multicolumn{6}{|l|}{ Mother's education level } \\
\hline Elementary education & $68.06 \pm 19.84$ & $80.25 \pm 14.41$ & $62.50 \pm 18.64$ & $86.00 \pm 18.72$ & $85.14 \pm 18.02$ \\
\hline Secondary education & $81.94 \pm 13.19$ & $86.11 \pm 13.06$ & $76.85 \pm 15.18$ & $89.72 \pm 10.17$ & $87.04 \pm 16.20$ \\
\hline Higher education & $75.60 \pm 18.99$ & $79.78 \pm 16.44$ & $69.98 \pm 18.09$ & $87.79 \pm 14.55$ & $82.67 \pm 21.022$ \\
\hline$P$-value & 0.459 & 0.572 & 0.097 & 0.965 & 0.393 \\
\hline \multicolumn{6}{|l|}{ Father's education level } \\
\hline Elementary education & $66.81 \pm 16.44$ & $82.00 \pm 13.58$ & $63.33 \pm 18.40$ & $83.50 \pm 18.31$ & $82.64 \pm 17.46$ \\
\hline Secondary education & $78.47 \pm 12.24$ & $77.75 \pm 12.93$ & $70.42 \pm 17.81$ & $91.13 \pm 9.56$ & $87.15 \pm 14.43$ \\
\hline Higher education & $76.84 \pm 20.22$ & $81.59 \pm 16.91$ & $71.47 \pm 17.97$ & $88.07 \pm 14.68$ & $83.26 \pm 21.65$ \\
\hline$P$-value & 0.273 & 0.926 & 0.387 & 0.459 & 0.892 \\
\hline
\end{tabular}

$S D$, standard deviation.

HRQOL for physical, emotional and social functioning were significantly different between patients with and without activity dysfunction $(P=0.000, P=0.030$, and $P=0.012$, respectively).

\section{DISCUSSION}

In the present study, we mainly focused on the physical conditions and psychological feelings of patients with KHE. We aimed to understand the influence of KHE on the daily life of children and their families, as well as their satisfaction with physiological, psychological and social adaptation functioning in patients and their families under the influence of disease. We also analyzed the HRQOL influencing factors to understand their real living conditions and internal feelings.

We found that patients with KHE had a lower HRQOL than those without. Patients aged $>24$ months showed differences in all scored entries, especially social functioning 
TABLE 7 | Analysis and score of each dimension of the PedsQL ${ }^{\mathrm{TM}} 4.0$ Generic Core Scale (age > 24 months).

\begin{tabular}{|c|c|c|c|c|}
\hline PedsQL ${ }^{\mathrm{TM}} 4.0$ Generic Core Scales & $\begin{array}{l}\text { Physical functioning } \\
\quad \text { (mean } \pm \text { SD) }\end{array}$ & $\begin{array}{l}\text { Emotional functioning } \\
\qquad \text { (mean } \pm \text { SD) }\end{array}$ & $\begin{array}{l}\text { Social functioning } \\
\quad(\text { mean } \pm \text { SD) }\end{array}$ & $\begin{array}{l}\text { School functioning } \\
\text { (mean } \pm \text { SD) }\end{array}$ \\
\hline Healthy children & $89.06 \pm 8.23$ & $85.48 \pm 13.47$ & $89.88 \pm 14.42$ & $91.38 \pm 9.19$ \\
\hline \multicolumn{5}{|l|}{ Patient group } \\
\hline With KMP & $64.46 \pm 22.03$ & $65.31 \pm 18.12$ & $69.38 \pm 18.79$ & $65.24 \pm 20.88$ \\
\hline Without KMP & $66.90 \pm 24.33$ & $73.41 \pm 18.22$ & $79.78 \pm 21.74$ & $71.49 \pm 21.13$ \\
\hline$P$-value & 0.979 & 0.270 & 0.470 & 0.582 \\
\hline Activity dysfunction & $50.35 \pm 22.89$ & $63.33 \pm 18.86$ & $64.72 \pm 21.93$ & $64.27 \pm 25.38$ \\
\hline Without activity dysfunction & $79.84 \pm 11.76$ & $76.00 \pm 16.11$ & $85.55 \pm 14.78$ & $73.14 \pm 15.23$ \\
\hline$P$-value & 0.000 & 0.030 & 0.012 & 0.091 \\
\hline \multicolumn{5}{|l|}{ Location } \\
\hline Extremity & $62.28 \pm 22.75$ & $74.64 \pm 20.61$ & $73.21 \pm 22.50$ & $67.44 \pm 20.36$ \\
\hline Trunk & $69.59 \pm 20.88$ & $70.00 \pm 16.04$ & $77.00 \pm 18.97$ & $68.94 \pm 17.60$ \\
\hline Head, face or neck & $65.28 \pm 28.62$ & $62.78 \pm 18.05$ & $76.11 \pm 23.69$ & $70.74 \pm 27.13$ \\
\hline$P$-value & 0.999 & 0.882 & 0.519 & 0.341 \\
\hline \multicolumn{5}{|l|}{ Mother's education level } \\
\hline Elementary education & $65.97 \pm 14.78$ & $78.89 \pm 16.91$ & $78.33 \pm 22.22$ & $68.52 \pm 13.88$ \\
\hline Secondary education & $76.39 \pm 21.60$ & $79.44 \pm 13.57$ & $85.56 \pm 12.61$ & $74.07 \pm 18.52$ \\
\hline Higher education & $61.10 \pm 26.00$ & $61.75 \pm 17.57$ & $69.50 \pm 22.12$ & $65.96 \pm 24.12$ \\
\hline$P$-value & 0.257 & 0.439 & 0.315 & 0.657 \\
\hline \multicolumn{5}{|l|}{ Father's education level } \\
\hline Elementary education & $55.68 \pm 23.79$ & $62.27 \pm 14.03$ & $70.91 \pm 18.00$ & $60.00 \pm 19.20$ \\
\hline Secondary education & $71.18 \pm 10.22$ & $78.33 \pm 18.54$ & $77.22 \pm 20.78$ & $73.52 \pm 9.84$ \\
\hline Higher education & $69.45 \pm 26.18$ & $70.56 \pm 19.55$ & $77.22 \pm 23.28$ & $71.33 \pm 25.78$ \\
\hline$P$-value & 0.347 & 0.148 & 0.761 & 0.568 \\
\hline
\end{tabular}

$S D$, standard deviation.

and cognitive functioning, compared with the normal control group. Children's self-consciousness and the development of psychological functioning gradually develop as they get older. Two-year-old children usually enter kindergarten and begin to develop social bonds with other children. However, because of their sickness-induced absence from school, they may feel inferior and lose confidence, ultimately resulting in a decline in performance. School social environment has a potential impact on HRQOL. Social support from classmates and teachers can promote the rehabilitation and long-term treatment adjustment of patients. Therefore, we encourage sick children to return to school and society as soon as possible when it is medically feasible. The disease duration of KHE may be long, which may affect patients' mental health and daily life. Therefore, additional efforts are needed to strengthen psychological support, reduce depression, and improve enthusiasm for learning in patients with KHE.

Parents of children with infantile hemangioma (a benign vascular tumor) often feel worried and anxious about their children's disease, especially parents of those with lesions on the face or other body parts that are not generally covered with clothes (15). However, in patients with KHE, we found that there was no significant difference in the HRQOL among patients with different lesion locations. This may be because KHE is a rare disease, and it is more difficult to treat than infantile hemangioma. These reasons may aggravate parents' anxiety and worry regardless of where the tumor is located. The prognosis of KHE was related to the tumor site, the degree of infiltration and the presence of KMP. Some patients without KMP will later develop KMP. Some patients with KMP will encounter further decreases in coagulation function. Patients without KMP may even experience a decreased range of motion. The presence of these complications suggests that the disease is progressing, and the morbidity rate will increase. As a consequence, parents may be concerned not only about the risk of disfigurement and the ridicule from other children but also about the child's health status itself. Therefore, it was not surprising that patients with KMP and activity dysfunction were associated with a relatively low HRQOL. Both factors affect patients' HRQOL.

One major concern of patients' parents is whether KHE can be effectively treated. Due to the lack of standard diagnosis and standard treatment, many patients with KHE do not receive appropriate treatment before referral (16). In general, the longer the disease progresses, the worse the HRQOL in children may be. Consistent with our previous study, we revealed that musculoskeletal complications occurred most commonly in older children (17). The destructive growth patterns associated with KHE and the infiltration of the muscles, connective tissues and joint structures can cause pain and functional limitations, all of which may affect a patient's abilities to perform routine daily activities. The difference 
between a patient and their peers can easily lead to the former experiencing negative social psychology, and patients with KHE may have difficulty establishing harmonious social relations. In addition, some children with effective initial treatment may later exhibit drug resistance, disease relapse or side effects. Going back and forth between hospitals and home greatly affects the physiological and psychological functioning of patients and parents, which may result in a decline in the HRQOL of children. We found that if KHE can be diagnosed at an early stage and in a timely manner, effective interventions can be applied (18). The incidence of complications and corresponding side effects of long-term treatment can be reduced. Moreover, psychosocial trauma can be prevented, and the long-term HRQOL of patients can be improved. If necessary, medical staff should provide necessary psychological intervention measures for patients at different ages.

When we evaluated the HRQOL in patients with KHE, we found that patients and their families had physical and psychological problems that affected their HRQOL. In this regard, treatment intervention should be carried out early. The improvement in the QOL can be used as a reference index to evaluate the therapeutic effect.

However, lesion location and the education level of the mother or father were not related to the HRQOL. Mothers are often the primary caregivers of children, and their emotional and psychological fluctuations can directly affect the psychological behavior of children. Although there was no statistical significance in the comparison of the educational experiences of mothers or fathers, it is interesting to note that the QOL scores of mothers with a primary education or higher were lower than those of mothers with only a secondary education. This may be due to the possibility that mothers with less than a primary education had insufficient knowledge of KHE, and it was difficult to obtain support and information related to the disease. Therefore, the cognitive function and psychological state of the child continue to deteriorate, leading to a decline in the HRQOL. However, mothers who obtain a higher education usually try to balance work and family and lack communication with their children, making it difficult for the children to receive appropriate nursing care and psychological care. Additionally, paying extra attention to a sick child consumes a mother's energy. The mother may be prone to excess anxiety, leading to a serious decline in the HRQOL.

Finally, we found that KMP and activity dysfunction were risk factors for a poor HRQOL in patients with KHE. For patients with these complications, good and targeted medical guidance and instructions can help them adjust their psychosocial and emotional conditions.

\section{REFERENCES}

1. Garcia-Monaco R, Giachetti A, Peralta O, Napoli N, Lobos P, Gioseffi L, et al. Kaposiform hemangioendothelioma with Kasabach-Merritt phenomenon:

\section{CONCLUSIONS}

The findings presented here suggest that KHE can influence the HRQOL in young patients and their parents. Patients with KHE and their parents generally have a poor HRQOL. Our results suggest that the combined use of the PedsQL ${ }^{\mathrm{TM}} 4.0$ Infant Scales, FIM and GCS is sufficient to evaluate QOL in children with KHE. In addition, our study provides novel findings that KMP and activity dysfunction are risk factors for HRQOL and life satisfaction. We hope that future multicenter, prospective data from a large sample will be collected to support and extend these findings, with the aim of improving the HRQOL in patients with KHE.

\section{DATA AVAILABILITY STATEMENT}

The raw data supporting the conclusions of this article will be made available by the authors, without undue reservation.

\section{ETHICS STATEMENT}

The studies involving human participants were reviewed and approved by the Ethics Committee of the West China Hospital of Sichuan University and the Ethics Committee of the Second West China Hospital of Sichuan University. Informed consent was obtained from the patients' parents. Written informed consent to participate in this study was provided by the participants' legal guardian/next of kin.

\section{AUTHOR CONTRIBUTIONS}

SD, KY, TQ, JZ, XZ, SC, LL, and YJ were involved in the initial conception and design of the study, data collection, and analysis of the data in this study. SD reviewed the literature and drafted the manuscript. LL and YJ reviewed the manuscript. All authors read and approved the final manuscript.

\section{FUNDING}

This project was supported in part by the National Natural Science Foundation of China (81401606 and 81400862), Key Project in the Science and Technology Program of Sichuan Province (2019YFS0322), Science Foundation for the Excellent Youth Scholars of Sichuan University (2015SU04A15), and 1.3.5 project for disciplines of excellence-Clinical Research Incubation Project of West China Hospital of Sichuan University (2019HXFH056).

\section{ACKNOWLEDGMENTS}

We thank all of the patients and their families for their kind cooperation with this work.

successful treatment with embolization and vincristine in two newborns. $J$ Vasc Interv Radiol. (2012) 23:417-22. doi: 10.1016/j.jvir.2011.12.007

2. Croteau SE, Liang MG, Kozakewich HP, Alomari AI, Fishman SJ, Mulliken JB, et al. Kaposiform hemangioendothelioma: atypical features and risks of 
Kasabach-Merritt phenomenon in 107 referrals. J Pediatr. (2013) 162:1427. doi: $10.1016 /$ j.jpeds.2012.06.044

3. O'Rafferty C, O'Regan GM, Irvine AD, Smith OP. Recent advances in the pathobiology and management of Kasabach-Merritt phenomenon. $\mathrm{Br} J$ Haematol. (2015) 171:38-51. doi: 10.1111/bjh.13557

4. Costa FD, Folpe AL. Intratesticular kaposiform haemangioendothelioma in adults: a report of two cases. J Clin Pathol. (2013) 66:6236. doi: 10.1136/jclinpath-2013-201478

5. Shabtaie SA, Wang B, Owyong M, Ruiz-Mesa C, Corrales-Medina FF, Rojas CP, et al. Neonatal kaposiform hemangioendothelioma of the spleen associated with Kasabach-Merritt phenomenon. J Pediatr Surg. (2016) 51:1047-50. doi: 10.1016/j.jpedsurg.2016.03.014

6. Mota JM, Scaranti M, Fonseca LG, Tolói DA, de Camargo VP, Munhoz RR. Response to paclitaxel in an adult patient with advanced kaposiform hemangioendothelioma. Case Rep Oncol. (2016) 9:481-7. doi: 10.1159/000448111

7. Nakaya T, Morita K, Kurata A, Ushiku T, Igarashi T, Kuroda M, et al. Multifocal kaposiform hemangioendothelioma in multiple visceral organs: an autopsy of 9-day-old female baby. Hum Pathol. (2014) 45:17737. doi: 10.1016/j.humpath.2014.03.019

8. Das A, Bansal D, Chatterjee D, Das A. Kaposiform hemangioendothelioma: Multifocal involvement, chylothorax, and kasabach-merritt phenomenon. J Pediatr Hematol Oncol. (2017) 39:1534. doi: 10.1097/MPH.0000000000000700

9. Varni James W, Limbers Christine A. The pediatric quality of life inventory: measuring pediatric health-related quality of life from the perspective of children and their parents. Pediatr Clin North Am. (2009) 56:84363. doi: 10.1016/j.pcl.2009.05.016

10. Varni JW, Seid M, Kurtin PS. PedsQL 4.0: reliability and validity of the pediatric quality of life inventory version 4.0 generic core scales in healthy and patient populations. Med Care. (2001) 39:80012. doi: 10.1097/00005650-200108000-00006

11. Ji Y, Chen S, Li K, Xiao N, Yang X, Zheng S, et al. Measuring health-related quality of life in children with cancer living in Mainland China: feasibility, reliability and validity of the Chinese Mandarin version of PedsQL 4.0 Generic Core Scales and 3.0 Cancer Module. Health Qual Life Outcomes. (2011) 9:103. doi: 10.1186/1477-7525-9-103

12. Hao Y, Tian Q, Lu Y, Chai Y, Rao S. Psychometric properties of the Chinese version of the Pediatric Quality of Life Inventory 4.0 generic core scales. Qual Life Res. (2010) 19:1229-33. doi: 10.1007/s11136-010-9672-y
13. Varni JW, Sherman SA, Burwinkle TM, Dickinson PE, Dixon P. The PedsQL Family Impact Module: preliminary reliability and validity. Health Qual Life Outcomes. (2004) 2:55. doi: 10.1186/1477-7525-2-55

14. Varni JW, Seid M, Rode CA. The PedsQL: measurement model for the pediatric quality of life inventory. Med Care. (1999) 37:126-39. doi: 10.1097/00005650-199902000-00003

15. Wang C, Li Y, Xiang B, Xiong F, Li K, Yang K, et al. Quality of life in children with infantile hemangioma: a case control study. Health Qual Life Outcomes. (2017) 15:221. doi: 10.1186/s12955-017-0772-z

16. Blatt J, McLean TW, Castellino SM, Burkhart CN. A review of contemporary options for medical management of hemangiomas, other vascular tumors, and vascular malformations. Pharmacol Ther. (2013) 139:327-33. doi: 10.1016/j.pharmthera.2013.05.001

17. Ji Y, Yang K, Chen S, Peng S, Lu G, Liu X. Musculoskeletal complication in kaposiform hemangioendothelioma without Kasabach-Merritt phenomenon: clinical characteristics and management. Cancer Manag Res. (2018) 10:332531. doi: 10.2147/CMAR.S171223

18. Ji Y, Yang K, Peng S, Chen S, Xiang B, Xu Z, et al. Kaposiform haemangioendothelioma: clinical features, complications and risk factors for Kasabach-Merritt phenomenon. Br J Dermatol. (2018) 179:45763. doi: 10.1111/bjd.16601

Conflict of Interest: The authors declare that the research was conducted in the absence of any commercial or financial relationships that could be construed as a potential conflict of interest.

Publisher's Note: All claims expressed in this article are solely those of the authors and do not necessarily represent those of their affiliated organizations, or those of the publisher, the editors and the reviewers. Any product that may be evaluated in this article, or claim that may be made by its manufacturer, is not guaranteed or endorsed by the publisher.

Copyright (c) 2022 Dai, Yang, Qiu, Zhou, Zhang, Chen, Li and Ji. This is an openaccess article distributed under the terms of the Creative Commons Attribution License (CC BY). The use, distribution or reproduction in other forums is permitted, provided the original author(s) and the copyright owner(s) are credited and that the original publication in this journal is cited, in accordance with accepted academic practice. No use, distribution or reproduction is permitted which does not comply with these terms. 